Revista de Ensino em Artes, Moda e Design

Dossiê 5

As fontes de pesquisa para moda. Uma aproximação interdisciplinar e arquivista da história da moda: pesquisa e ensino.

\title{
GRUPO TEATRAL DESENCANTO DE TRINDADE, GOIÁS: ENTRE CENAS, REUSO E SUSTENTABILIDADE
}

\author{
DESENCANTO FROM TRINDADE THEATER \\ GROUP, GOIÁS: between scenes, reuse and \\ sustainability
}

\section{GROUPE DE THÉÂTRE DE DÉSENCHANTEMENT DE TRINDADE-GOIÁS: entre scènes, réutilisation et durabilité}

\section{Poliene Soares dos Santos Bicalho'}

Nélia Cristina Pinheiro Finotti ${ }^{2}$

Josana de Castro Peixoto ${ }^{3}$

\footnotetext{
1 Doutora em História Social pela Universidade de Brasília (UEG). Docente pelo Programa de Pós-Graduação em Territórios e Expressões Culturais no Cerrado (TECCER/UEG).

E-mail: poliene.soares@gmail.com | Lattes: http://lattes.cnpq.br/8387718307836391 | Orcid: http://orcid.org/0000-0002-8324-8743

2 Mestranda no programa de Pós-Graduação Stricto Sensu em Territórios e Expressões Culturais no Cerrado. Universidade Estadual de Goiás (UEG), especialista em docência Universitária pela Universo-Goiás, Graduada em Design de Moda pela Universo-Goiás. Participante do grupo de estudos GEFOPI.

E-mail: neliaueg@gmail.com | Lattes: http://lattes.cnpq.br/275330576250579 | Orcid: http://orcid.org/0000-0002-4946-651X

3 Doutora em Ciências Biológicas pela Universidade Federal de Goiás (UFG). Docente pelo Programa de Pós-graduação em Território e Expressões culturais do Cerrado (TECCER-UEG) e Programa de Pós-graduação em Sociedade, Tecnologia e Meio Ambiente (PPG STMA-UniEVANGELICA).

E-mail: josana.peixoto@gmail.com | Lattes: http://lattes.cnpq.br/1480725200366013 | Orcid: http://orcid.org/0000-0002-3496-1315
} 


\title{
Resumo
}

Este trabalho tem como objetivo analisar como as ações de sustentabilidade são utilizadas no processo de produção dos figurinos do Grupo Teatral Desencanto. Este grupo iniciou suas atividades no ano de 1988 e, desde então, organiza os principais movimentos culturais da cidade de Trindade, em Goiás, apresentando-se em eventos regionais, nacionais e internacionais. O Desencanto trabalha com várias questões sociais, seja nos processos de construção das vestimentas, nas apresentações culturais ou na qualificação profissional. O problema deste artigo se desenrolou em torno da seguinte questão: como as ações de sustentabilidade são utilizadas no processo de produção dos figurinos do Grupo Teatral Desencanto? A metodologia seguiu a abordagem qualitativa e interpretativa, associada à pesquisa bibliográfica e ao estudo de caso. A relevância da pesquisa situa-se na perspectiva de fomentar reflexões que contribuam para uma melhor compreensão da sustentabilidade na construção de figurinos teatrais. A análise permite afirmar que, durante o processo de criação e produção dos figurinos, acessórios, alegorias e cenários, o Grupo desenvolve ações sustentáveis - em sua maioria, de forma inconsciente, já que as praticam tendo em vista o viés financeiro, direcionado à economia de recursos.

Palavras-Chave: Grupo Teatral Desencanto. Vestimentas. Sustentabilidade.

\begin{abstract}
This paper aims to analyze how sustainability actions are used in the production process of the Desencanto Theater Group costumes. This group started its activities in 1988, since then, organizes the main cultural movements of the city of Trindade, Goias, and performs at regional, national and international events. The Desencanto group works with various social issues, whether in the construction process of clothing, cultural presentations or professional qualification. The problem of this article was developed around the following question: how are sustainability actions used in the production process of Desencanto Theater Group costumes? The methodology followed the qualitative and interpretative approach, associated with bibliographic research and case study. The relevance of the research lies in the perspective of fostering reflections that contribute to a better understanding of sustainability in the construction of theatrical costumes. The analysis allows us to state that, during the process of creating and producing costumes, accessories, allegories and scenarios, the group develops sustainable actions, mostly unconsciously, as it practices them in view of the financial bias for the economy of resources.
\end{abstract}

Key-words: Desencanto Theater Group. Clothes. Sustainability.

\section{Résumé}

Cet article vise à analyser la manière dont les actions de développement durable sont utilisées dans le processus de production des costumes du groupe de théâtre Desencanto. Ce groupe a commencé ses activités en 1988 et, depuis lors, organise les principaux mouvements culturels de la ville de Trindade, Goiás, lors de manifestations régionales, nationales et internationales. Le Desencanto fonctionne avec diverses questions sociales, que ce soit dans le processus de construction de vêtements, de présentations culturelles ou de qualifications professionnelles. Le problème de cet article s'articule autour de la question suivante : comment les actions de développement durable sont-elles utilisées dans le processus de production des costumes du groupe de théâtre Desencanto? La méthodologie a suivi l'approche qualitative et interprétative, associée à la recherche bibliographique et à l'étude de cas. La pertinence de la recherche réside dans la perspective de susciter des réflexions qui contribuent à une meilleure compréhension de la durabilité dans la construction de costumes de théâtre. L'analyse nous permet d'affirmer que, dans le processus de création et de production de costumes, accessoires, allégories et scénarios, le Groupe développe des actions durables - la plupart inconsciemment, telles qu'elles sont pratiquées compte tenu de leur prédisposition financière à l'économie des ressources.

Móts-clés: Groupe de théâtre Desencanto. Vêtements. La durabilité. 


\section{INTRODUÇÃO}

Trindade. Metodologicamente, delimitamos para este artigo o recorte temporal de 2018 a 2019.

Neste sentido, o problema central da pesquisa está assim formulado: como as ações de sustentabilidade são utilizadas no processo de produção dos figurinos do Grupo Teatral Desencanto?

A metodologia centrou-se nas abordagens qualitativa e interpretativa, paralelamente à pesquisa bibliográfica e ao estudo de caso. Para Severino (2007, p. 121), estudo de caso é "pesquisa que se concentra no estudo de um caso particular, considerado representativo de um conjunto de casos análogos, por ele significativamente representativo". Assim, o estudo de caso se centrou no Grupo Teatral Desencanto, com delimitação nas ações realizadas no "Carnaval de Rua - Escola de Samba Acadêmicos de Trindade". (2019) O levantamento e a construção dos dados se deram por meio de quatro instrumentos distintos: I - levantamento de imagens dos figurinos produzidas pelo grupo in loco e de documentos, como jornais, fotos do acervo do grupo etc.; II - observação e registros fotográficos dos processos de construção das vestimentas para análise do uso das técnicas sustentáveis em sua produção; III - elaboração e realização de 07 (sete) entrevistas semiestruturadas com os componentes do grupo que planejam e desenvolvem os figurinos; e IV - a produção de um relato de experiência do próprio Grupo Teatral, no qual foram apresentadas as teias de produção e o reaproveitamento dos figurinos do grupo. A pesquisa foi realizada nos meses de novembro de 2018 a março de 2019. Ressaltamos que a análise dos dados se deu ao longo do processo e as informações foram analisadas à luz das teorias que sustentam a pesquisa.

Para as contribuições teóricas, utilizou-se o estudo de moda e sua relação com a sustentabilidade, de Berlim (2016), apoiando nas questões de sustentabilidade e suas ações na produção de produtos de Fletcher e Grose (2011); a análise de uma ideia geral do que é sustentabilidade e seus desafios, novas maneiras de entender o processo de construção de produtos de moda e o que é moda ética para Salcedo (2014); a discussão do tema de desenvolvimento de produtos sustentáveis a partir da fase de conscientização acerca da centralidade estratégica da sustentabilidade ambiental, dos estudos de Manzini e Vezzoli (2016); conceitos de história da indumentária, vestimenta, moda e cultura para Barthes (2005); contribuições sobre teatro e traje de cena de Viana e Muniz (2012); e Viana e Bassi (2014); e sobre o carnaval, os estudos de Da Matta (1997).

Para melhor compreensão dos figurinos produzidos pelo grupo Desencanto, vamos fazer uma apresentação dos conceitos de moda, indumentária, vestimenta, roupa, traje e figurino. Nesse ínterim, abordar conceitos de sustentabilidade, técnicas e ações possiveis para serem consideradas sustentáveis na conceptualização da moda e como pode ser vista na construção de figurinos.

No contexto do figurino, este pode ser visto de forma bem permanente e não passageiro, como a moda, pois estes utilizam recursos de aproveitamentos de vestimentas e produtos que foram moda em alguma época da história. Ou mesmo a traje social pode tornar se traje de cena a partir do momento que ele é utilizado como representação teatral. Assim, observam-se relações estreitas entre vestimenta, traje de cena e corpo.

Ao final da pesquisa, a análise nos permitiu afirmar que, durante o processo de criação e produção dos figurinos, acessórios, alegorias e cenários, o Grupo Desencanto 
desenvolve ações sustentáveis, em sua maioria de forma inconsciente, considerando que as pratiquem levando em conta o viés financeiro.

\section{HISTORICIDADE DO GRUPO TEATRAL DESENCANTO DE TRINDADE- -GOIÁS}

Para melhor compreensão do objeto e da discussão proposta, faz-se necessário apresentar o Grupo Teatral Desencanto, que surgiu da ideia de três jovens idealistas, liderados por Amarildo Jacinto, em 1986. Logo de início, começaram a colocar em prática suas ideias, desenvolvendo suas encenações em forma de pequenos laboratórios, brincadeiras e, empiricamente, construindo seus figurinos. A estreia aconteceu no dia 05 de fevereiro de 1988, com a principal peça teatral intitulada "Por Ironia do Destino".

Na sequencia, o grupo percebe que precisa se organizar como uma empresa, ou seja, precisa ter registro, pois até o momento era, somente, um grupo teatral, sem identificação jurídica. Percebendo que precisavam se fortalecer, os integrantes decidiram se registrar como uma associação cultural que tem por base um grupo de teatro que a movimenta completamente.

Atualmente, o Desencanto é uma associação composta pela diretoria, formada por 23 (vinte e três) pessoas, as quais movimentam o dia a dia da associação, a qual, por sua vez, é formada por 186 (cento e oitante e seis) pessoas diariamente. Além disso, há mais 1.214 (um mil e duzentos e quatorze) pessoas cadastradas em atividades diversas. Destas fazem parte integrantes do processo de realização, de criação de figurinos e de cenários estético-teatrais das referidas festividades da cidade.

Segundo informações obtidas em entrevista realizada com o diretor Amarildo Jacinto, em 16 de novembro de 2018, na sede do Grupo Desencanto, em Trindade Goiás, o Desencanto é o maior grupo cultural voluntário do Estado de Goiás e é um dos maiores do Brasil. Possui um acervo de obras de arte (pinturas e esculturas) produzidas por eles, além de objetos, cenários, recursos cênicos e estrutura organizacional inigualável, que foi construída ao longo dos 30 (trinta) anos de trabalho. O Grupo realiza trabalhos expressivos, mobilizando parte significativa da comunidade local na construção de vestimentas, figurinos, acessórios, adornos, artes (escultura e pintura), carros alegóricos e demais alegorias.

Um dos maiores espetáculos do Desencanto é a encenação da Vida, Paixão e Morte de Jesus Cristo, realizada na Rodovia GO-060, conhecida como Rodovia dos Romeiros, entre Goiânia e Trindade. Na encenação, conferem cenários gigantescos, realizados em um palco inusitado, contendo painéis pintados pelo artista Omar Souto e estendidos pelos $17 \mathrm{Km}$ de Rodovia. As cenas acontecem na Sexta-feira da Paixão, com cerca de 600 (seiscentos) atores, figurantes e técnicos, dentre estes, atores, bailarinos, músicos e artistas plásticos de diferentes faixais etárias, nível de escolaridade e classes sociais. Com atores do povo para o povo, encenando em uma mistura de arte e fé, como relata o diretor de arte Amarildo Jacinto, em entrevista de 2018, ao afirmar que "esta forma de encenação é única no mundo".

A partir da Associação, o Grupo passou a oferecer à sociedade cursos, oficinas de teatro, danças, produção de esculturas e pinturas (com o intuito de realizar ações sociais sem fins lucrativos). Também são desenvolvidos os textos, as criações, a produção dos cenários e das vestimentas, momentos em que acontece uma rede de sociabilidades 
que envolvem toda a comunidade no processo de construção destes figurinos.

Dentre as múltiplas atuações do grupo, fizemos um recorte, para a nossa investigação, no Carnaval de Rua da Escola de Samba Acadêmicos de Trindade, que pertence ao Grupo Desencanto, e iniciou suas encenações em 1988, em forma de brincadeiras, como descreve Amarildo Jacinto, em entrevista: "a cidade não possuía um carnaval para que a comunidade pudesse brincar. Neste contexto, organizamos umas fantasias e o Grupo foi para as ruas para apresentar um carnaval", ou seja, o grupo estava ali se apresentando, pois não havia nenhuma pretensão de ser uma escola de samba submetida a avaliações ou premiações no sentido carnavalesco, mas sim com o objetivo de levar arte e cultura para a comunidade, onde todos poderiam participar; além do objetivo de proporcionar um espetáculo teatral participativo entre atores e comunidade.

Assim, na sequencia, o texto busca expor as diferenciações entre moda, indumentária, vestimenta e figurino, de modo a evidenciar que o vestuário faz parte das mais variadas atividades do grupo teatral em estudo, entre outros, sejam elas tradicionais ou cotidianas.

\section{MODA, INDUMENTÁRIA, VESTIMENTA E FIGURINO}

Ainda é plausível apreender a roupa como uma vestimenta, que é investigada pela indumentária de uma época na qual se tornou obsoleta diante da moda. Estas estão ligadas ao corpo, ao ser humano, seja por uma representação, necessidade, desejo ou simplesmente pelo poder. Ainda é possível fazer uma relação entre moda e figurino, sendo que o figurino está ligado ao corpo real e a moda a corpo ideal, mas estes configuram como objeto de comunicação, representação de imagens e mensagens visuais.

Ao pensarmos nas roupas, normalmente a primeira ideia que surge faz referência à moda, no entanto, o vestuário possui usos diversos. Ao se pensar a roupa como documento, deve-se atentar para os diversos papéis que ela assume na sociedade. Assim sendo, neste texto, busco apresentar os conceitos dessas variadas nomenclaturas que cobrem o corpo, a fim de melhor compreender suas funções e significados na elaboração do espetáculo estudo, do Grupo Teatral Desencanto.

Ao analisar a história da moda, usos e costumes de vários países, há algo em comum entre os figurinos do grupo, ou seja, das mais primitivas às mais modernas servem para comunicar elementos pessoais e sociais, assim como destaca Sant'Anna (2016, p. 10) quando diz que "a compreensão historiográfica da moda ultrapassa a visão superficial da mesma e a entendemos enquanto um ethos presente entre os sujeitos sociais, fazendo-os pautar suas relações a partir da aparência".

Esteticamente, essas vestimentas emitem sinais e muitas possuem significados simbólicos que facilitam a compreensão de um determinado povo e de uma época. Quanto a isso, complementa Viana e Bassi (2014, p. 19), "a construção da indumentária permite vislumbrar a cultura da qual saiu ou está inserida". Ainda vale ressaltar a contribuição de Carlyle (s/a, apud SVENDSEN, 2010, p. 09), que aponta que

...tudo quanto existem, tudo que representa Espirito para Espirito, é propriamente uma Roupa, um Traje ou Vestimenta, vestida para uma estação, e a ser posta de lado. Assim, nesse importante assunto das ROUPAS, devidamente compreendido, inclui-se tudo que o homem pensou, sonhou, fez e foi: todo o universo exterior e o que ele contém nada é senão Vestimentas; e a essência de toda Ciência reside na filosofia das ROUPAS. 
Neste contexto, infere-se que, apesar de sua importância, as roupas demoraram a se tornar de interesse dos pesquisadores, mas, ainda assim, tem sido retratada e debatida como um subsídio para diversas áreas do conhecimento. Quanto ao Grupo Teatral Desencanto, busca-se, por meio dessa pesquisa, apresentar os contextos históricos e sociais inerentes às suas encenações, que retratam acontecimentos importantes para a história da humanidade.

De acordo com Laver (1989), a relevância em compreender as roupas é antiga, pois começou a partir do Antigo Egito. A indumentária estabelecia uma diferenciação entre classes sociais, política e religiosidade, características estas que sobreviveram por vários períodos e que se mantém concisa até os dias de hoje. Também é caracterizada por transformações periódicas que afetam os setores da vida social, tanto o vestuário quanto política, religião, artes e estética.

$\mathrm{O}$ fenômeno chamado moda teve seu início no século $\mathrm{XV}$, quando o homem percebe o seu valor individual e a necessidade de se diferenciar um do outro. Partindo de uma necessidade de diferenciação, o homem criou diversos tipos de vestimentas para se destacar, usando os tecidos de várias formas, misturando cores e, sem saber, criando uma moda para cada época. Até os anos 1990, a moda era conhecida e diferenciada por uma década específica, mas, a partir dos anos 2000, passou a ser compreendida por uma multiplicidade de estilos. Também passou a evidenciar uma diversidade de usos e modos de agir, seja de um povo, de um lugar, de uma determinada cultura ou sociedade.

Neste contexto, Barthes (2005, p. 257) contribui ao relatar que, "até o início do século XIX, não houve história da indumentária, propriamente dita, mas apenas estudos de arqueologia antiga ou recensões de trajes por qualidade". O autor ainda explicita que

\begin{abstract}
...os trabalhos propriamente científicos sobre indumentária apareceram por volta de 1860; são trabalhos de eruditos, de arquivistas, em geral medievalistas; seu principal objetivo é retratar a indumentária como uma soma de peças, a peça indumentária e, sim, como uma espécie de acontecimento histórico, convido, antes de tudo, datar seu aparecimento e dar sua origem circunstancial. (BARTHES 2005, p. 258).
\end{abstract}

Barthes (2005) ainda esclarece que a indumentária teve origem romântica e que fornecia aos artistas, pintores e teatrólogos da época as informações figurativas da "cor local, necessária para suas obras, os pesquisadores queriam [...] estabelecer alguma equivalência entre a forma da indumentária e o espirito geral de um tempo ou de um lugar, caráter moral, ambiência, estilo etc" (p. 257-258).

A roupa e a história estão interligadas. Ao discorrer sobre as vestimentas, é preciso voltar ao passado e analisar a história dos seres humanos e de como estes se vestiam. No início, as pessoas apenas cobriam o corpo, seja por pudor ou proteção, mas, a partir do século XV, surge o termo moda, segundo Palomino (2003). Anteriormente, havia somente as terminologias vestimentas e indumentárias, ainda que, indubitavelmente, estas transitem lado a lado, pois estão ligadas ao corpo, à pele. Ainda é possível inferir que nada está tão próximo ao corpo como a roupa, podendo ser aclamada como uma segunda pele.

O vestuário não pode ser analisado por si só ou fora do seu uso cotidiano, pois possui vários adjetivos e não pode ser considerado como algo insignificante ou meramente inocente, pois traz consigo objetivos a serem atingidos. Assim apresenta Müller (2000), afirmando que quem o interpreta o faz segundo uma época, a expressão de uma 
ideia, a crítica de uma sociedade. O Grupo Desencanto apresenta em seus figurinos e cenários objetos de valor atribuídos em contato com o corpo físico, passando, por sua vez, a dialogar; ou, como afirma Cidreira (2005), o vestuário é um prolongamento da morfologia, uma incorporação do corpo.

Ainda, assegura-se que a vestimenta, por ser um símbolo iconográfico e uma ampliação corporal, impõe a quem a usa uma "lei informal". Logo, pode-se dizer que o vestuário faz o corpo passivo ao seu discurso. Desse modo, entende-se que a vestimenta é uma maneira de comunicação que vai além do indivíduo para sociedade, pois que se torna um discurso do corpo com a simbologia da roupa. Conrado (2010, p. 25) corrobora com tal definição ao pontuar que

\begin{abstract}
Vestir-se é uma maneira de produzir discursos a respeito de si mesmo. Quando nos vestimos há, inclusive, um diálogo entre nosso corpo e a roupa que vestimos. Não é fato que a mesma roupa pode se ajustar perfeitamente bem em uma pessoa e parecer ridícula quando vestida por outra? O modo como nos vestimos nos faz parecer mais solenes, se usamos roupas mais solenes, ou mais esportivos, se dessa forma nos vestimos. Quando nos vestimos, assim como quando escrevemos uma carta, oferecemos ao mundo "chaves" de leitura e interpretação.
\end{abstract}

E perceptível que a vestimenta é o ato de vestir, cobrir o corpo; a roupa é, pois, o que vestimos ou com o que cobrimos o corpo. Dessa forma, é possível afirmar que a roupa tem uma representação estética, cultural, sendo ela direcionada para um fenômeno sociológico universal. Na compreensão de Godart (2010, p. 29),

\begin{abstract}
...a moda, pelo fato de emergir de tensões no cerne da dinâmica social, e porque ela contribui para a solução, torna-se então uma "matriz", por meio da qual podemos compreender os fatos sociais, em vez de vê-la apenas como um epifenômeno superficial do vestuário.
\end{abstract}

Assim, é plausível inferir que, a partir do momento em que o indivíduo sente o corpo coberto com determinada vestimenta, ele detém o domínio e o poder por ela expressa, seja por estilos estéticos, seja por representações sociais e culturais; independente se se refere a uma alegoria ou a um figurino para representação ou um look de moda individualizado. Leon-Potilha (2012 apud BICALHO, 2018, p. 91) corrobora com tal inferência ao afirmar que "a vestimenta é abordada como expressão artística, não só pela beleza, mas também pelo preciosismo e pelos sentidos diversos inerentes ao processo de criação e produção destes".

Percorrendo este caminho, tem-se o termo indumentária, que, historicamente, surge antes do termo moda. Até o Renascimento não havia o terno moda e sim indumentária, que, segundo Simili e Vasques (2013), trata-se de um conjunto de vestuário que caracteriza uma sociedade em um determinado período; diferente do traje, que diz respeito somente à roupa. Nesse sentido, ainda conceitua Conrado (2010, p. 23): "a indumentária, nesse caso, seria o componente normativo do vestuário. Aquilo que indica um grupo, um modo de vestir codificado, anterior à própria experiência particular do indivíduo". Essas vestimentas estão ligadas ao corpo, ao ser humano, seja por uma representação, necessidade, desejo ou simplesmente pelo poder.

Ainda é necessário relatar outra categoria da roupa, vestimenta, indumentária ou moda, seja de uma época passada ou atual: trata-se daquela que é utilizada com outro valor, ou seja, é representativa de todos estes anteriores, o figurino, o traje de cena ou o traje de folguedo. Para uma melhor compreensão, Viana e Bassi (2014, p. 11) destacam que 


\begin{abstract}
...o traje de cena é definido como a indumentária das artes cênicas". O termo é mais amplo que traje teatral, pode abranger trajes de teatro, dança, circo, mimica, performance, shows e espetáculos. [...] O traje de folguedo é a indumentária usada nas festas, nas brincadeiras de caráter popular, entra aqui os trajes folclóricos, festas populares cristãs, afro-brasileiras e ibéricas.
\end{abstract}

E notável a multiplicidade de estilos e nomeclaturas para as vestimentas das artes cênicas. Mas elas têm um mesmo objetivo: comunicar-se, expressar algo, conforme esclarece Castilho (2014 apud VIANA; BASSI, 2014), ao pontuar que em cada cultura se observam formas de organizações e produções de imagens que ganham significados socioculturais e de representações das raizes de pensamentos, e estes se constituem no imaginário e se revelam nos elaborados trajes e adormos como modos de narrar e representar histórias e valores. Ainda segundo a autora, essas representações são das mais variadas culturas, formas de marcar, pintar, vestir ou adormar o corpo, de modo que há "[...] uma rede de significados estraordinários que ganham singularidades e se expressam por meio de trajes culturais, trajes típicos, trajes festivos ou ainda folclóricos ou de foguedos" (p. 09).

Nesta mesma vertente, Bustamante (2008 apud LINKE, 2013, p. 43)1 esclarece que

\begin{abstract}
...o figurino é mais do que um simples traje, mais que uma roupa, pois ele possui uma bagagem, um repertório, um conjunto de mensagens implícitas visíveis e que não ultrapassa o limite sobre todo o panorama do espetáculo, além de possuir funções específicas dentro do contexto e perante o público.
\end{abstract}

A arte de vestir-se, aqui representada por figurino ou traje de cena, é uma expressão artística que nos possibilita conhecer parte da nossa história, dos valores de nossa cultura. Nesse sentido, ser parte integrante do Grupo Teatral Desencanto, ou mesmo seus expectadores, é também uma maneira de compreender um pouco as histórias e os valores da cultura do povo goiano, especialmente os que habitam a região de Trindade, e também a região conhecida como Grande Goiânia, que compreende os municípios circunvizinhos muito próximos à capital goiana.

O figurino pode ser compreendido como um conjunto das vestimentas e acessórios, ou tudo que compõe aquele personagem a ser interpretado. A maquiagem, assim como o cenário, deve complementar o traje de cena. Neste contexto, Abrantes (2001, p. 09) observa que "o figurino apresenta características sugestivas indispensáveis para manter o clima plástico que os elementos cênicos instauram no palco". Os figurinos têm função de seduzir a plateia, ou seja, apresentar, por meio das vestimentas, o contexto que está sendo encenado, pois estão carregadas de elementos que possibilitam a compreensão de um período histórico, social e econômico. Para Berthold (2014, p. 2), "o encanto mágico do teatro, num sentido mais amplo, está na capacidade inexaurível de apresentar-se aos olhos do público sem revelar seu segredo pessoal”. Ainda sobre o figurino, acrescenta Leite (2012, apud VIANA; MUNIZ, 2012, p. 293), afirmando tratar-se de "um sistema vestimentar com regras próprias, referente a diversos sistemas vestimentares, os quais estão relacionados com culturas presentes e passadas". Sobre o vestuário, esclarecem Viana e Muniz (2012, p. 293):

...nos diversos sistemas de vestuário, passados e presentes, a utilização social e simbólica do vestuário está presente na especialização do traje pelo gênero e pelas idades da vida; o status social se afirma pelas categorias de trabalho e intercambio, e também pela ritualização do cotidiano, expressa através dos

1 http://www.cih.uem.br/anais/2013/trabalhos/188_trabalho.pdf 
acontecimentos sociais: ritos de passagem, expressão de sentimentos, saúde, festas, lazer, esporte, entre outras.

Neste argumento, infere-se que a roupa, independente da função a ela destinada, apresenta um contexto social e, nesse sentido, a sustentabilidade é um desmembramento desse contexto sobre o qual não se pode deixar de pensar. Este assunto pode ainda não estar disseminado entre os criadores, principalmente para os trajes de cena, mas é indubitável que a sustentabilidade é um desafio para o momento de criação e produção dos trajes.

\subsection{SUSTENTABILIDADE: UM DESAFIO PARA A CRIAÇÃO DE FIGURINOS}

O Conceito de sustentabilidade, no amplo universo de criação dos figurinos, é um assunto que pode ser apreciado por diversos autores do campo da moda, pois, no quesito sustentabilidade em figurinos, há uma escassez de bibliografias específicas; embora o figurino, de diferentes maneiras, resulte de várias ações sustentáveis em seu contexto histórico, visto que a reutilização de trajes é hábito antigo do teatro ocidental. Ainda hoje a reutilização é prática corrente em diversos grupos de teatro, principalmente com a utilização dos três erres: reduzir, reciclar e reutilizar. Deste modo, faz-se necessário uma breve discussão sobre o surgimento da sustentabilidade na moda para compreendermos a sustentabilidade nos figurinos.

O termo sustentabilidade surgiu durante as décadas de 1960 e 1970, quando os ambientalistas passaram a dar voz às suas preocupações acerca do impacto e devastação provocados pela sociedade consumista; e, assim, surgiu o interesse em se descobrir alternativas mais sustentáveis para a produção e o consumo (GWILT, 2014). É clara a importância do termo sustentabilidade para o desenvolvimento de produtos, pois não é apenas a exploração do meio ambiente que está em questão; pode-se compreender para além, como elucida Jatobá (2014, p. 9): "sustentabilidade, literalmente, significa 'manter alguma coisa viva e conectada com seu meio'. Todos os seres e os elementos vivos tem a capacidade de se sustentar e conviver". É necessário, pois, pensar em medidas para prevenir e mitigar impactos, associados ao equilíbrio adequado das alterações ambientais fatais.

Para uma melhor compreensão do termo, Salcedo (2014, p. 14) salienta que "sustentabilidade é o desenvolvimento que satisfaz as necessidades do presente sem comprometer a satisfação das necessidades das gerações futuras". A sustentabilidade pode ser compreendida por muitos criadores pelos seus discursos vazios, pois, geralmente, é tratada como marketing para agregar valor aos seus produtos e, normalmente, não estão efetivamente desenvolvendo ações de sustentabilidade, que minimizem o impacto que o consumo exacerbado tem provocado, principalmente no mercado da moda. Nesta vertente, Berlim (2016, p. 24) enfatiza que "sem o conhecimento e os estudos necessários para discutir a questão, e diante da emergência do tema, o risco de nos depararmos com discursos vazios é grande". A autora ainda acrescenta que, neste sentido, "[...] novas formas de consumo estão se estabelecendo por meio de interações não mais entre consumidores e empresas, mas entre usuários, criadores e designers" (p. 57).

É preciso, então, uma reflexão mais profunda calcada na efeméride da moda; na simples rotina do cotidiano; no questionamento sobre a durabilidade do produto; na questão do ciclo deste produto; o que se veste; o que se consome, ou seja, deve-se 
pensar em alternativas para o desperdício e o descarte. Sobre a escassez de recursos naturais, Gwilt (2014, p. 20) observa que "uma estratégia de design sustentável pode ser empregada por um designer com o objetivo de colaborar na redução dos impactos ambientais e/ou sociais associados à produção e ao uso de descarte de um produto".

Destarte, é proeminente a importância de conhecer técnicas que possam minimizar esses impactos causados pelas vestimentas mediante nossas ações, para o que Jatobá (2014) afirma existirem técnicas a serem desenvolvidas, tais como: Zero Waste (desperdício Zero), reciclagem, o reaproveitamento e o upcycling (reutilização de materiais). Corrobora com esta ideia Manzini e Vezzoli (2016, p. 55), ao emitirem a seguinte observação:

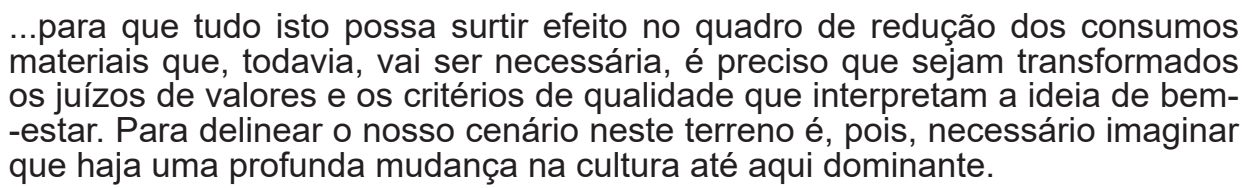

Contudo, a mudança de cultura não acontece de forma rápida, posto que há uma tendência de soluções que possam definir requisitos gerais considerados sustentáveis. Para as autoras Fletcher e Grose (2011), há uma grande preocupação no que tange às matérias primas utilizadas na produção de vestuários e com a quantidade de energia e produtos químicos utilizados no cultivo das fibras. A exploração de materiais tem sido o ponto de início para a maior parte da inovação sustentável na moda. Pode-se afirmar que há estudos que indicam à urgência de se trabalhar a sustentabilidade. Para Lipovetsky (2003), os produtos de moda, talvez, sejam aqueles de menor e mais frágil vida útil, pois são geridos dentro da lógica da moda, um sistema que dignifica o presente e a efemeridade, sendo o temporal que produz a modernidade e a sociedade de consumo; a faceta de sua lógica é a efemeridade e um dos seus fundamentos é a obsolescência.

Os figurinos do Grupo Desencanto também podem ter um descarte muito rápido, ou uma rotatividade de personagens e adequações de tamanhos. Nesta conjuntura, surge a necessidade e a possibilidades de reaproveitamento destes figurinos, pois, como defende Berlim (2016, p. 25), "é necessário que exista consciência do impacto das nossas escolhas, e observar o consumo desenfreado da sociedade, pois vestimos plantas, pelos de bichos, saliva de lagartas e petróleo".

Diante da pesquisa realizada, inferimos que as ações de sustentabilidade são de caráter interdisciplinar e, dentro desta conjuntura, é de responsabilidade de todos que estão inseridos nos ciclos de produção desenvolver e utilizar os figurinos conscientemente. Para além, é preciso considerar, com maior amplitude, qual é seu papel (deste grupo em estudo e dos tantos outros inseridos no mundo, seja na produção de figurinos e/ou de moda) diante destas mudanças. Nesta perspectiva, torna-se cada vez mais intensa a ideia de que somente com atitudes e ações éticas será possível à construção de uma sociedade sustentável, e a educação tem um papel basilar nisso.

Neste ínterim, na próxima seção, passa-se à narrativa de como são produzidos os figurinos do Grupo Teatral Desencanto para o carnaval de rua de 2019, dentro do prisma da sustentabilidade, fazendo sempre um paralelo entre sustentabilidade e figurinos.

\section{RESULTADOS}

A aplicabilidade empírica de nossa pesquisa aconteceu entre os meses de novembro de 2018 e março de 2019, consistindo em acompanhar o processo de criação 
e desenvolvimento dos figurinos para o Carnaval de rua do ano de 2019. Para além, foram realizadas entrevistas semiestruturadas com 7 componentes do grupo ${ }^{2}$, sendo: 1 . Amarildo Jacinto, Diretor de Artes e fundador do grupo; 2. Rodrigo Gomes Magalhães da Cunha, Diretor-Presidente que está no grupo desde 1991; 3. Romilda Aparecida Souza, que faz parte de todo o processo de construção dos figurinos desde 1986; 4. Maria Helena Gomes Magalhães, bordadeira do grupo desde 1986; 5. Leandro Carvalho Arantes, responsável pela área de comunicação e que está no grupo desde 1998; 6. Juliana A. Mendanha, que produz as vestimentas e participa desde 2015; e 7. Walisson Domingos da Silva, que produz as vestimentas e está no grupo desde 2016. Os entrevistados participam tanto dos processos de desenvolvimento do figurino como das encenações enquanto atores.

O Grupo Desencanto apresenta, na avenida principal da cidade, a encenação do Carnaval de Rua da Escola de Samba Acadêmicos de Trindade. Todos os anos, a partir do mês de agosto, tem início o planejamento para a construção dos figurinos na sede do Grupo, que se transforma em uma fábrica de sonhos e fantasias. São criados enredos ricos em detalhes quando os componentes do grupo e a comunidade local se unem para transformar as pesquisas em ideias; e estas começam a ganhar vida com desenhos, modelagens e peças pilotos, transformando a ideia inicial em realidade, por meio de bordados com miçangas, paetês e lantejoulas; confecção de adornos; dentre outros. O Carnaval é celebrado com estilo e beleza, produzindo um toque especial na avenida e o tornando um evento de arte e cultura.

O idealizador da Escola de Samba Acadêmicos de Trindade, Amarildo Jacinto $(2019)^{3}$, relata que a estreia nas ruas foi em 1988 e que, a cada ano, o tema que dá origem ao enredo é encenado por diversas alas em carros alegóricos, e vivido por participantes e produtores. Os adornos e os carros alegóricos são elementos que promovem o encanto da referida escola com seus estilos diversificados. O grupo busca, em seus temas, apresentar uma inspiração que seja cultural, de interesse da comunidade e que possa informar, questionar ou simplesmente brincar, conforme corrobora Treptow (2003, p. 86), enfatizando que o "tema é a história, o argumento, a inspiração de uma coleção".

No ano de 2018, o Grupo trouxe um enredo que se referia às atividades de arte e cultura da escola dos últimos 30 anos, trabalhando as cores da escola, vermelho e dourado, com o tema "Desencanto 30 anos de Arte e Cultura", uma homenagem entre brilho, cores e tambores. O samba contou o enredo "A Deus, nosso agradecimento maioral, 30 anos se passaram", constituindo-se em uma simbologia representativa do local. Neste sentido, como apresenta Da Matta (1997), o Carnaval é tomado como rito nacional, fundado na possibilidade de dramatizar valores globais, críticos e abrangentes da nossa sociedade. O autor afirma que "o rito das asas ao plano social e inventa, talvez, sua mais profunda realidade" (p. 31). Para dar vida e cor aos figurinos, a escola contou com a participação dos integrantes do grupo e da comunidade para o desenvolvimento dos figurinos e de todos os blocos do Carnaval. A escola apresentou 8 (oito) alas, 6 (seis) carros alegóricos e a comissão de frente, mostrando os grandes eventos do grupo.

No ano de 2019, o Grupo homenageou as questões folclóricas brasileiras, pois, em entrevista, Amarildo Jacinto relata que "o folclore brasileiro de todas as regiões foi 2 A pesquisa passou pelo Conselho de Ética da Universidade Estadual de Goiás, obtendo aprovação para que fossem realizadas as entrevistas com os componentes do grupo. Os entrevistados assinaram o Termo de Consentimento Livre e Esclarecido para que pudessem ser divulgados seus relatos e nomes.

3 Entrevista no dia 29 de janeiro de 2019 na sede do Grupo Desencanto em Trindade Goiás. 
valorizado em suas formas e ritmos. Foram divididas em blocos, como: frevo, maracatu, samba de roda, fogaréu, cavalhadas, dentre outros". Como esclarece Amarildo, é realizada uma reunião para definição do tema a ser trabalhando e, na condição de diretor de artes, ele instiga os demais a pesquisar. Com o tema "Expressão Popular - Arte do Povo" começaram os trabalhos, que são divididos em vários blocos, com um responsável para cada ação a ser executada.

Pensando em reaproveitar os materiais já existentes no acervo do Grupo, os envolvidos no processo criativo buscam possibilidades a serem apresentadas e discutidas entre os componentes, como aponta Rodrigo, Diretor-Presidente (2019) ${ }^{4}$, ao enfatizar que, no desfile, para o carro da cavalhada, foram utilizados materiais alternativos, como caixas de papelão para cobrir toda a base do veiculo.

Foi observado in loco que o Grupo Desencanto cria seguindo uma metodologia para o planejamento e desenvolvimento dos figurinos e alegorias; e, nestes processos, desenvolvem ações sustentáveis, mesmo que de forma inconsciente, no que tange a um conhecimento teórico prévio sobre o tema. Para tanto, é necessário seguir algumas etapas de planejamento e desenvolvimento do figurino: ter um projeto, planejamento, pesquisas diversas, ou seja, um briefing. De acordo com Seivewright (2015, p.10), "Briefing é o início de qualquer projeto criativo, e o projeto é um conjunto de atividades que, normalmente, segue um cronograma. O objetivo [...] é, em essência, inspirar e delinear as metas e as premissas requeridas."

A criatividade é um fator essencial para o reaproveitamento dos figurinos, assim, Munari (1998) complementa ressaltando que a criatividade não significa improvisação sem método, deve ser exercitada a partir de várias formas e fontes, de várias ordens. $A$ criatividade envolve pesquisa, conhecimentos de algo novo ou do passado, obtido após leituras, visitações ou observações e, sobretudo, com registros de informações. Ainda sobre a criatividade, Berzbach (2013, p. 09) corrobora com essa ideia, enfatizando que "pisicólogos definem criatividade como produção de ideias novas e apropriadas, em todos os âmbitos da atividade humana ".

Na fase das pesquisas do Desencanto, as informções são colocadas em paineis imagéticos, que, para Martin (2012), são necessários para selecionar as linhas e os temas a serem explorados, ou seja, para dar vida à ideia é preciso passá-la para o papel. A partir das informações dos paineis, começa o processo de criação dos figurinos, os esboços, de tal modo que as ideias vão se formando e tomando vida por meio dos desenhos. Tudo o que compõe o figruino deve ser retratado para mostrar adequadamente as qualidades básicas do que se destina a representar, ou seja, devem ser detalhadas as silhuetas, cores, texturas, materiais, entre outros. Nesta fase, é necessário pensar o que se tem para reaproveitar, quais as técnicas sustentáveis podem ser utilizadas; logo, há uma necessicidade de espeficicações técnicas para começar a produção do figurino. Para Martin (2012), é na ficha técnica que são incluídas várias opções de cores ou amostras de tecidos, aviamentos e demais materias e detalhes que serão utilizados no figurino.

Estes processos são realizados para os produtos de moda, contudo, para os figurinos não são diferentes, desta forma, o processo de construção se inicia após as pesquisas, quando são construídos os desenhos e passa-se à aprovação pelo Diretor de

4 Entrevista no dia 29 de janeiro de 2019 na sede do Grupo Desencanto em Trindade Goiás. 
Artes e, em seguida, começa o processo de construção. Mesmo não apresentados anteriormente, existem outros processos fundamentais, como: modelagem, corte, costura, acabamentos e superfícies bordadas, como relata a entrevistada Romilda costureira. 0 Grupo Desencanto, por meio da Associação, desenvolve seus figurinos manualmente, com horas de trabalho e dedicação, seja interna ou externamente.

Em relação aos figurinos, faz parte da construção: desenhar, angariar materiais, modelar, costurar, bordar ou reciclar o que se tem no acervo do Grupo. Neste sentido, Rodrigo, Diretor-Presidente, esclarece que dessa construção fazem parte professoras, costureiras, artistas, donas de casa, enfim, membros da comunidade que são integrantes do Grupo. Diante de pesquisa in loco, evidenciou-se que, em sua maioria, são utilizados materiais recicláveis ou adquiridos com o patrocínio da Prefeitura e doações de empresas que garantem a realização dos eventos. De acordo com a entrevistada Maria Helena, bordadeira, eles reaproveitam materiais disponíveis, recicláveis e figurinos antigos para a produção dos atuais.

Para a análise das técnicas de sustentabilidade, foram eleitas 3 (três) categorias: acessórios de cabeça, vestimentas e carro alegórico. Quanto aos assessórios de cabeça, o entrevistado Leandro elucida que todos são reaproveitados; não jogam nada fora e tudo que é utilizado pelo Grupo é guardado para ser reutilizado em outros momentos de encenação. Há vários elementos no acervo do Grupo, tal como a plumária, que é um elemento riquíssimo para os figurinos.

As plumagens utilizadas pelo Grupo são naturais, ou seja, são penas de amimais, armazenadas em um acervo das mais variadas cores e tamanhos. De acordo com a quantidade em estoque, como informou o Diretor-Presidente, há muito tempo não são compradas mais penas, de modo que as existentes vêm sendo reutilizadas nos últimos 30 anos, e ele acredita serão utilizadas por muitos mais anos anida. Porém, aos poucos o Grupo tem buscado outros materiais que deem um efeito similar, a exemplo das penas sintéticas, que podem ser pintadas com produtos naturais. Amarildo explica que estão utilizando outros materiais para fazer a representação das penas, como a pena de faisão feita de TNT, retalhos ou o que tiver disponível de material; aproveitam estampas, bordados, recortam e depois pregam em palitos. Nesse ano, a porta bandeira não utilizou nada de penas de amimais, pois estas foram construídas com os materiais mencionados, como pode ser visto na Figura 1, que expõe a utilização de penas artificias em vários elementos dos figurinos.

Figura 1 - Penas artificiais, confeccionadas de materiais alternativos.

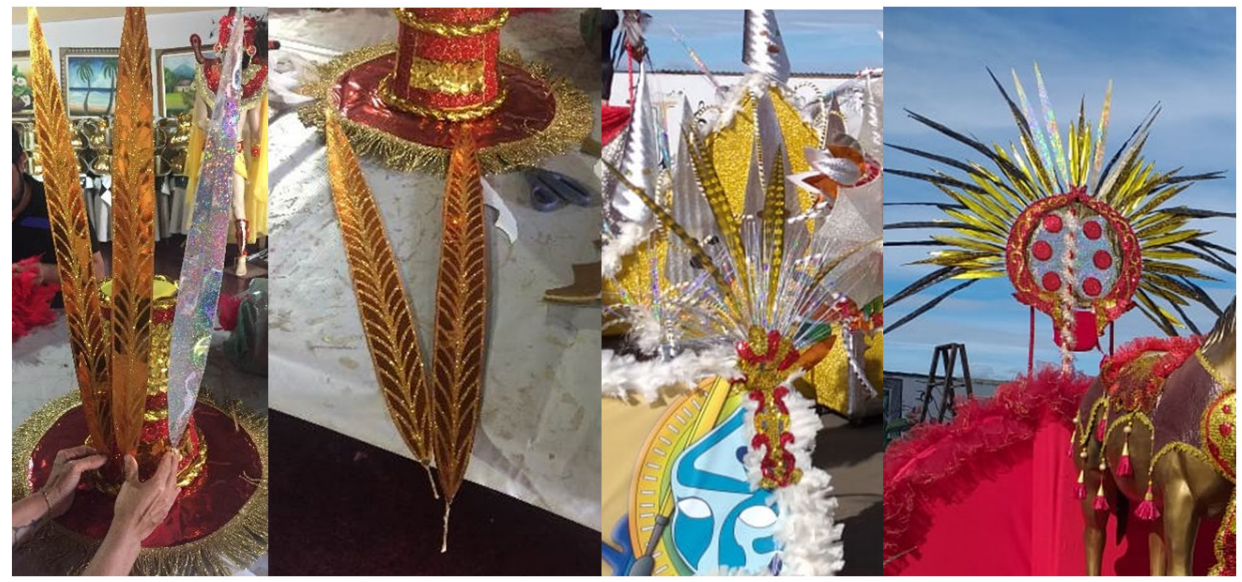

Fonte: Arquivo do Grupo Desencanto (2019). 
Neste contexto, Amarildo ressalta: "vamos trabalhar ecologicamente, não comprando mais penas de animais, fazendo pesquisa para apresentar um trabalho interessante, bacana, e que não contribuem para a destruição do meio ambiente". O Grupo tem mostrado a preocupação ecológica também no reaproveitamento de elementos utilizados em outros desfiles, como alguns adereços de cabeça do Carnaval de 2018 reutilizados em 2019, conforme ilustra a Figura 2 e 3.

Figura 2 - Acessórios de cabeça utilizados em desfile de 2018.

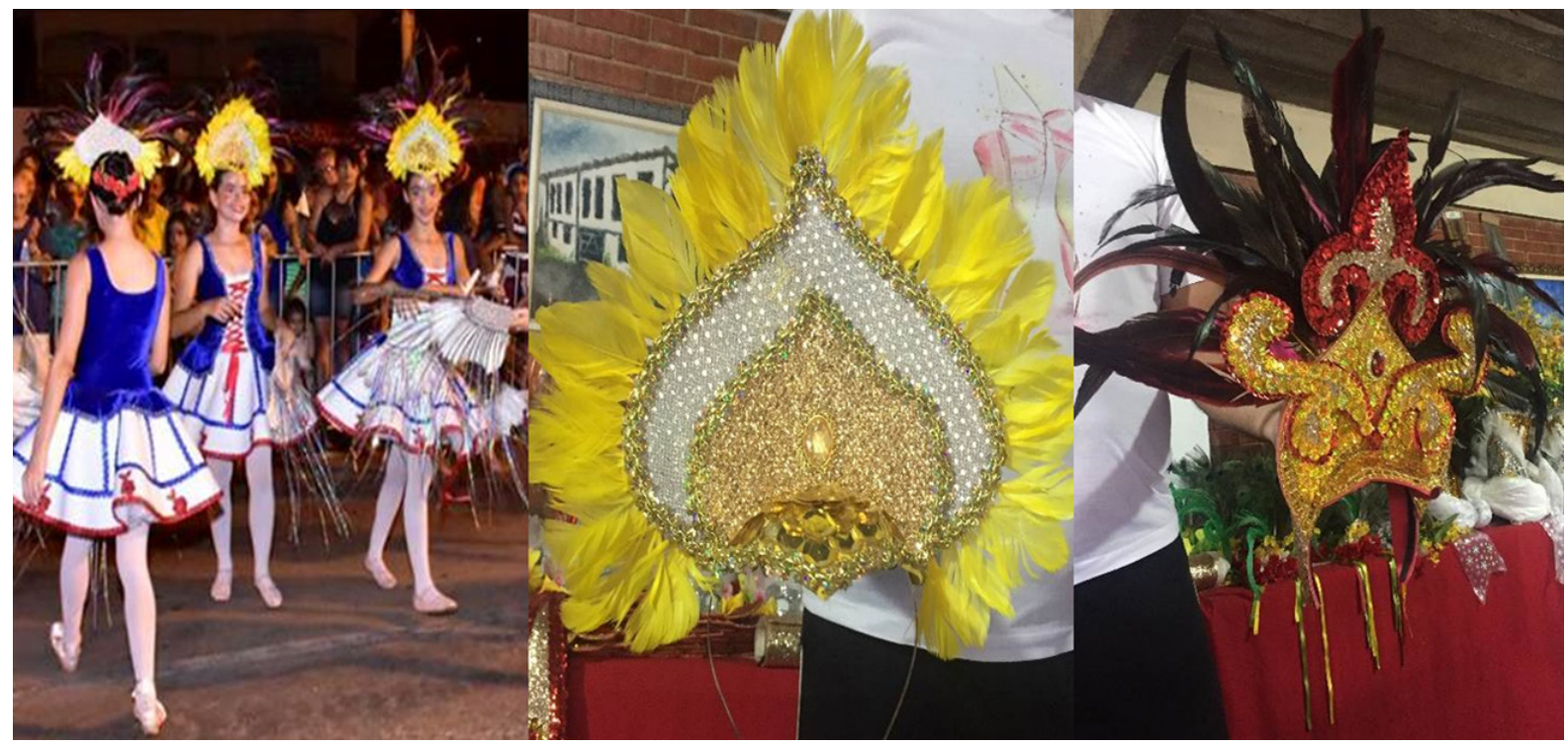

Fonte: Arquivo do Grupo Desencanto (2019).

A Figura 2 apresenta uma estrutura de cabeça das bailarinas do bloco da Comissão de Frente, com penas amarelas e roxas, durante a apresentação em 2018. Em 2019, este acessório foi aproveitado em dois momentos do desfile: as penas roxas foram colocadas no figurino do frevo, conforme a Figura 3; e a base do adereço foi aproveitada tanto no frevo quanto no acessório de cabeça das baianas, conforme a Figura 4.

Figura 3 - Bloco do Frevo com reaproveitamento de acessórios de cabeça.

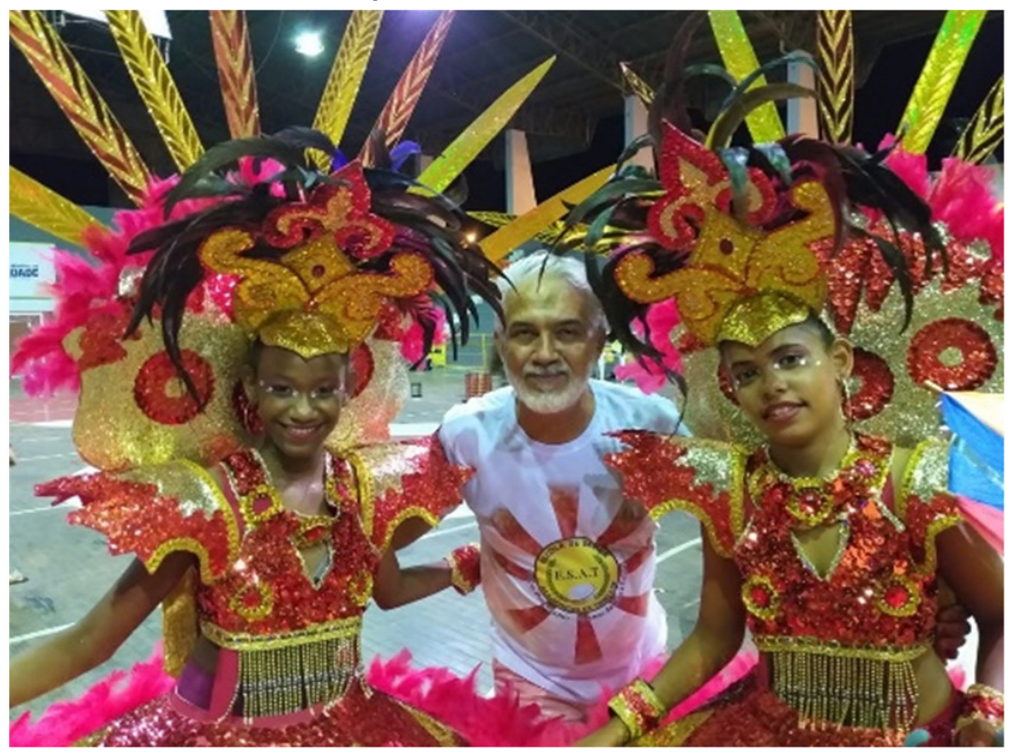

Fonte: Arquivo do Grupo Desencanto (2019). 
Figura 4 - Acessórios das Baianas.
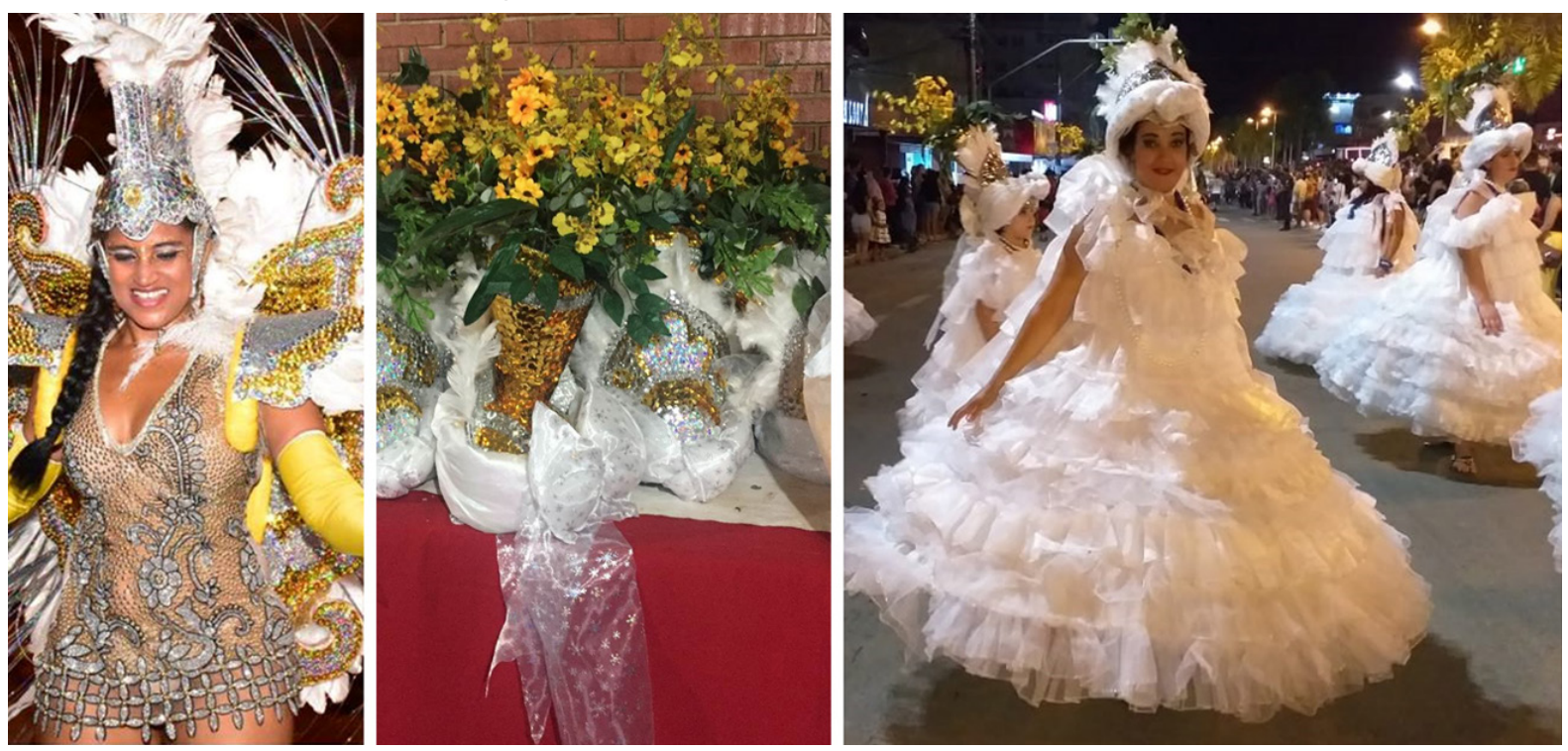

Fonte: Arquivo do Grupo Desencanto (2019).

O Diretor-Presidente, Rodrigo, esclarece que o acessório de cabeça das baianas, em 2019, foi reaproveitado de dois acessórios de cabeça do ano anterior. Como pode ser observado na Figura 4, a estrutura da frente, utilizada em 2018, tornou-se a estrutura da parte traseira das baianas; e a base da parte da frente é a mesma estrutura apresentada na Figura 3 e utilizada pelas bailarinas da Comissão de Frente. É perceptível, tanto pela pesquisa in loco quanto pelas imagens de arquivo, que o Grupo Desencanto faz uso de várias ações sustentáveis em seus processos de criação e construção de figurinos e cenários.

Nas vestimentas também se aproveita muito de outras já usadas, como alega o Diretor de Arte Amarildo. A peça apresentada na Figura 5, por exemplo, está há nove anos na peça teatral Caminhada da Fé e, a cada ano, ela passa por reciclagem. Este ano, a peça veio para o Carnaval, o que demonstra o trânsito dos figurinos em outros espaços, ou seja, entre várias atividades do Grupo, pois não há uma separação rígida destes figurinos, podendo estar em várias representações. Amarildo elucida, neste sentido, que "tudo para todas as encenações é reaproveitado, reciclando ou simplesmente trazendo a peça para outro contexto, na qual não se percebe a repetição destes elementos pelo público". 
Figura 5 - Reaproveitamento das vestimentas.
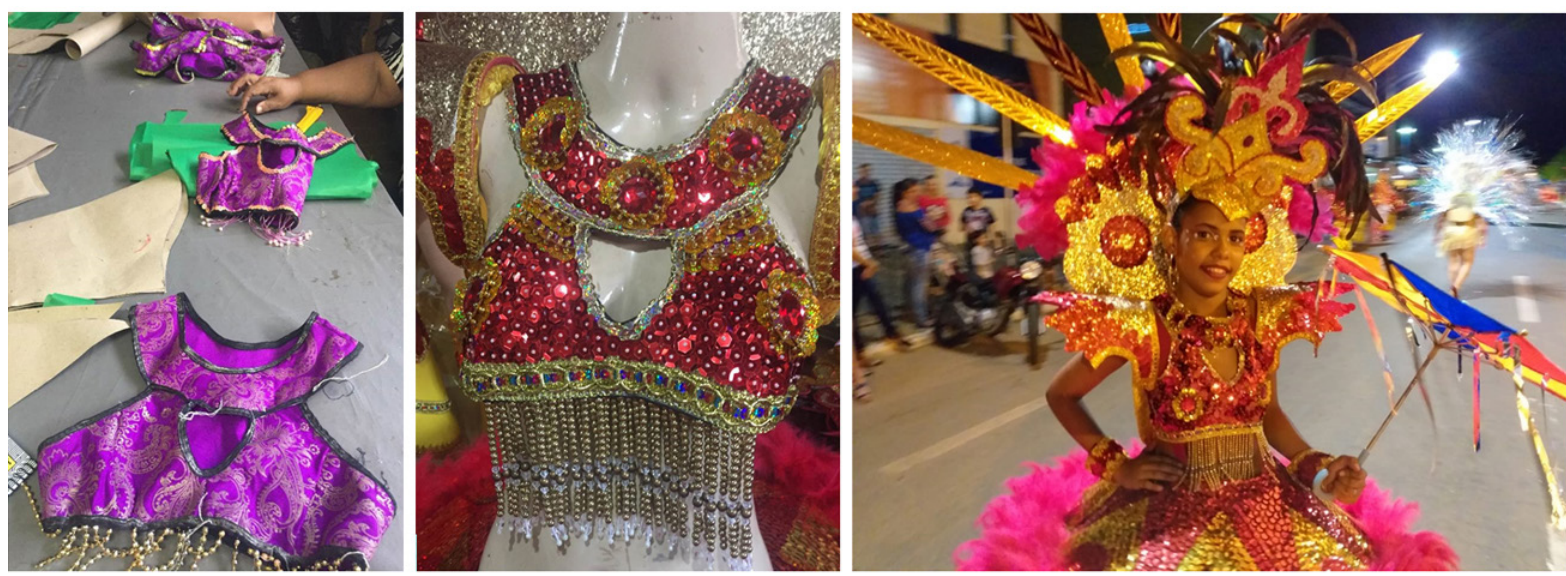

Fonte: Arquivo do Grupo Desencanto (2019).

Amarildo destaca ainda que, quando se trabalha com cultura há um movimento grande de aproveitamento em todos os sentidos, enfatizando que

...busco ideias, transformo tudo, de forma que consigo resolver toda a situação de falta de recursos para as representações do grupo. Também não fico com estoque grande sem ter uso, não descartamos praticamente nada, pois acreditamos que vamos utilizar, seja qual for o material ele é guardado e pensado no momento de desenvolver um figurino para cada encenação.

Outro entrevistado, Wallison, que produz os figurinos, anuncia que os carros alegóricos, em suas bases, são todos reaproveitados, ou seja, sua estrutura é mantida e o restante é reelaborado. Para a reconstrução, pode ser utilizado mais material alternativo, pois não estão diretamente em contato com o corpo. O Grupo tem pensado várias estratégias para reconstruir esses carros alegóricos que precisam ficar esteticamente apresentáveis, de modo a brilhar aos olhos dos espectadores. Para além, buscam alternativas econômicas para a construção, pois, em sua maioria, são peças muito grandes e que necessitam de muito material para serem adornados. Neste sentido, são buscados materiais alternativos que, geralmente, são reciclados e reaproveitados, como acrescenta Amarildo, destacando que "vamos aproveitar aquilo que vai para o lixo, estamos buscando estes materiais a algum tempo, tem muitas pessoas contribuindo".

Para este ano, foi utilizado o papelão para cobrir toda a base dos carros; copos descartáveis para dar estrutura; marmitas de alumínio para dar o efeito do brilho; garrafas plásticas foram transformadas em flores; palhas de milho se transformaram em cobertura e acabamento; e o capim também foi utilizado como forro para os demais ornamentos, como está apresentado na Figura 6. 
Figura 6 - Carro alegórico com material reciclado.

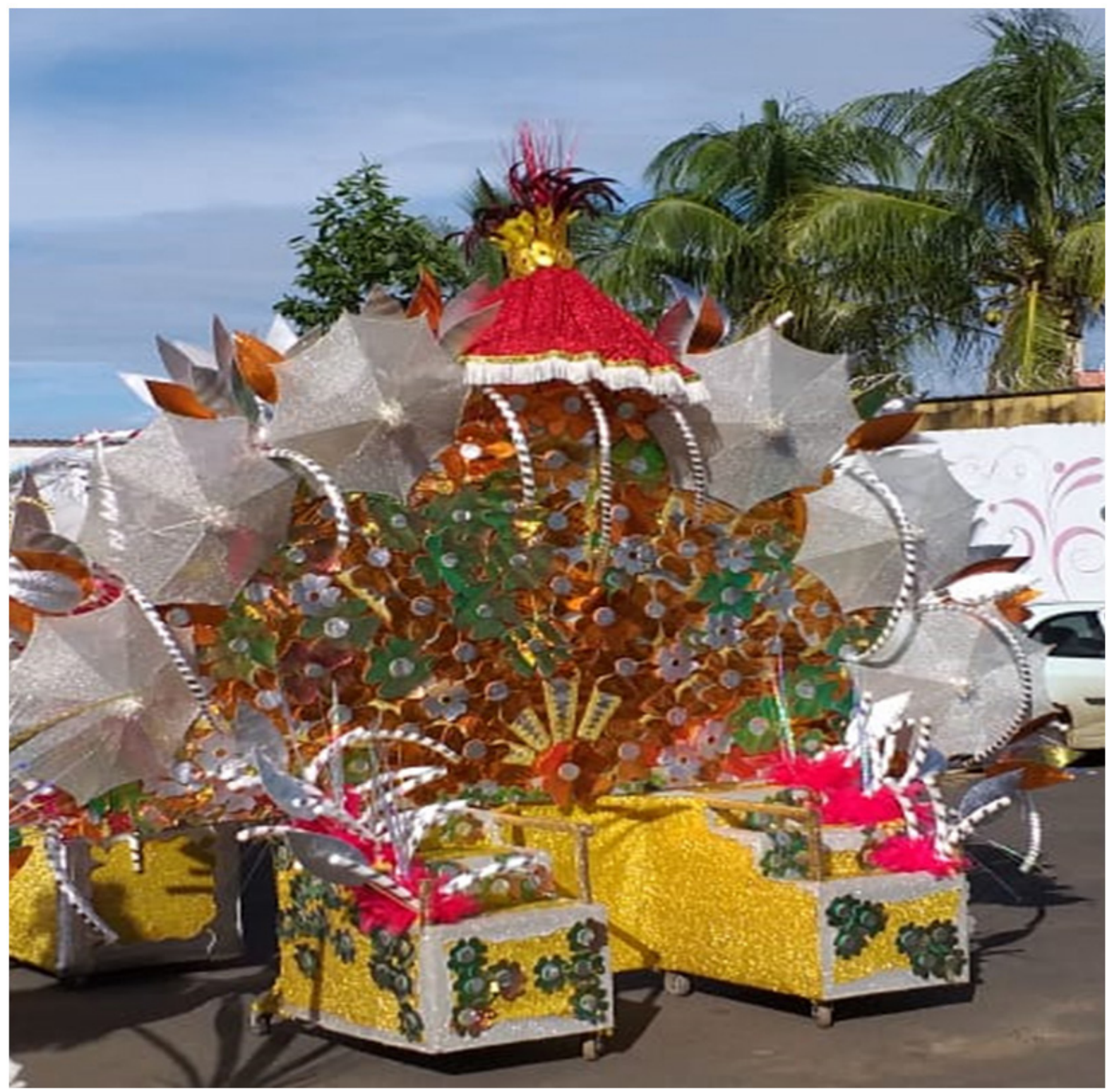

Fonte: Arquivo do Grupo Desencanto (2019).

Diante do exposto, pode-se compreender que o Grupo Desencanto utiliza várias técnicas sustentáveis no processo de produção de seus figurinos. Ficou perceptível que essas técnicas, que são utilizadas também na moda, são por eles desconhecidas do ponto de vista teórico; porém, eles fazem usos delas tais, como Upcycling, que consiste no reaproveitamento de objetos e materiais para criar novos itens, muitas vezes com funções diferentes, sem alterar as principais características do objeto original. Inferimos que o Grupo trabalha com a técnica do slow fashion ${ }^{5}$, pois trabalham com a forma lenta de descarte, quase nula, ou seja, seus produtos são construídos por eles mesmos, tornando-se elementos de afetividade, com vida prolongada e não para o simples descarte, conforme destaca Amarildo, alegando que "preciso de materiais que tem vida longa, deve ser utilizado muitas vezes, de várias maneiras, um material que me dê segurança, que terei por muito tempo". 
Em relação à reciclagem, o Grupo desenvolve várias peças teatrais a partir de material reciclável, lixo reciclável e resíduo reciclável, estes são transformados em materiais úteis, reciclados tecnologicamente ou manualmente, para que se tenha uma nova função dentro do processo criativo, dando uma nova vida útil ao produto que seria descartado, como também agregam a ele valor estético. In loco, percebe-se que a estética de um figurino, independente de qual função exerça, é o primeiro item a ser visualizado, mas quando são utilizadas técnicas sustentáveis, é preciso maior análise, pois o lixo precisa virar luxo. Desse modo, as pessoas envolvidas no projeto demonstram satisfação ao desenvolver um figurino novo com base nos velhos. Nesta perspectiva, Carli e Venzon (2012, p. 87) relatam que a sustentabilidade

\begin{abstract}
...analisa e mede a eficiência dos processos produtivos, considerando as tendências de maior geração de benefícios, com menor uso de recursos. As três dimensões comprometem-se nas suas ações, a conjugar os três Rs da sustentabilidade: reduzir, reutilizar e reciclar, engajando-se no desenvolvimento econômico sustentável.
\end{abstract}

Essa percepção sustentável e as demais questões ambientais não são alheias ao Grupo Desencanto, pois a equipe está inserida nesse contexto e passou a valorizar e refletir sobre o impacto social de suas ações. Contudo, não é uma percepção consciente, posto que, em entrevista, os sete participantes do Grupo, ao serem perguntados se conheciam e praticavam técnicas sustentáveis na produção dos figurinos, todos responderam que não. Ao serem questionados sobre as ações sustentáveis que praticam, relataram que fazem o processo de reaproveitar simplesmente por questões financeiras.

Ao questionar o Diretor de Arte, Amarildo, se as pessoas que trabalham com ele no processo de desenvolvimento dos figurinos possuem consciência do reaproveitamento por questões ambientais, ou se simplesmente o fazem por falta de materiais novos, ele relatou que

\begin{abstract}
...estas questões ambientais são muito novas para eles, temos uma discussão muito antiga de reaproveitar. Vejo que o mundo hoje está muito difícil, mesmo que inconscientemente temos que trabalhar com as questões de reaproveitar tudo, é necessário começar a fomentar estas questões no grupo.
\end{abstract}

Amarildo ainda observa, nesse sentido, que "falar que o grupo é 100\% consciente das questões ambientais, não é, mais existe atualmente uma discussão em cima destas questões".

Ao se estabelecer um paralelo entre figurino e moda, observa-se que neste último campo há um diálogo entre as questões ambientais, principalmente por se tratar a moda como algo efêmero, passageiro, onde o descarte acontece de forma rápida e a oferta de novos produtos é constante no mercado capitalista, que precisa girar. Quanto à construção de um figurino, percebe-se que a sustentabilidade acontece de forma contraria, quase que de forma involuntária, ou seja, as ações de sustentabilidade, tão almejadas na moda, na elaboração do figurino é recorrente em suas encenações, seja por razões ambientais, sociais e/ou econômicas.

Assim, a pesquisa aponta que as ações de sustentabilidade, utilizadas no processo de produção dos figurinos do Grupo Teatral Desencanto, acontecem ainda de forma prática e não totalmente consciente, visto que o Grupo utiliza várias técnicas sustentáveis, embora não à luz de uma conscientização teórica relativa à sustentabilidade prioritariamente, mas sim por questões financeiras direcionadas à economia de materiais. 


\section{CONSIDERAÇÕES FINAIS}

Ao ponderar sobre a história do Grupo Desencanto e a predominância do conteúdo analisado por meio do Carnaval de rua, é perceptível o gestar de uma identidade cultural e social por meio das vestimentas; e, para além, em seus processos de construção dos figurinos utilizando técnicas sustentáveis.

As performances realizadas pelo Grupo estão em constante mudança e transitam entre vários lugares e espaços. Portanto, há uma necessidade de reaproveitar e, entre os diversos tipos de apresentações do Grupo, há duas em destaque: a Caminhada da Fé e o Carnaval de Rua. Nessas apresentações, os figurinos transitam de uma para outra, tendo em vista a dinamicidade da criatividade humana, do reciclar, além da busca por excelência no trabalho a baixo custo de produção.

Para muitos participantes, o conceito de sustentabilidade ainda não é muito claro quando se fala em figurino, pois, ao ser questionado sobre sustentabilidade a maioria sempre coloca questões relacionadas à moda, que foi tratada aqui apenas para estabelecer algumas conexões e paralelos com o figurino, que é o objeto central da pesquisa e análise. Entretanto, o Grupo Desencanto experiencia este conceito ao praticar ações de sustentabilidade em suas produções. Para além, os integrantes do Grupo poderão produzir um novo discurso sobre estes movimentos ambientais, de modo a tomar consciência e valorizar estas atividades, se autoconscientizando sobre a importância do que estão fazendo para o mundo ao contribuir para minimizar os impactos ambientas no nosso planeta; e que é possível reaproveitar sempre, independente da técnica, tanto no figurino quanto na moda.

É perceptível que o Grupo se reinventa por meio das redes de sociabilidades, no processo de construção dos figurinos e de encenações. Diante disso, entende-se que o ser humano cria formas infindáveis de transformação de si e do seu meio, tudo isso entrelaçado com o social, que também se ressignifica o tempo todo.

Ressalta-se, ainda, que o Desencanto executa ações de sustentabilidade inconscientemente, visto que são os fatores econômicos que os motivam originalmente, por falta de recursos financeiros, o que os levam a reaproveitar tudo, logo, não partem de uma consciência racionalmente construída relativa à sustentabilidade. $E$, tendo em vista a sustentabilidade, é possível fazer uma relação entre figurino e moda? Ficou evidenciado que as técnicas que são utilizadas na moda são utilizadas também no figurino, porém, é importante destacar que a moda e o figurino só conseguem construir relações quando estamos falando de técnicas de sustentabilidade, ou no caso de um figurino para uma encenação atual, contemporânea. Mesmo assim seria uma relação com características distintas, pois o figurino não possui compromisso com o sistema da moda.

Portanto, esperamos que essa pesquisa possa trazer ao Grupo e à comunidade inserida neste movimento uma clareza de que estão sendo utilizadas técnicas, consideradas por muitos autores, como sustentáveis; e, assim, fomentar este conceito entre os pares. Dessa forma, espera-se agregar valor aos figurinos por eles desenvolvidos, seja esse valor de consciência ambiental ou de melhorarias para o mundo, nos aspectos que vão além do social e do econômico, porque suas técnicas de sustentabilidade no processo de produção dos figurinos vão muito além das questões econômicas, resultando em práticas também de sustentabilidade, efetivamente. 


\section{REFERÊNCIAS}

ABRANTES, Samuel. Heróis e Bufões: o figurino encena. Rio de Janeiro: Agora da llha, 2001.

BARTHES, Roland. Imagem e Moda. São Paulo: Martins Fontes, 2005.

BERLIM, Lilyan. Moda e sustentabilidade: uma reflexão necessária. São Paulo: Estação das Letras e Cores. 2016.

BERTHOLD, Margot. História mundial do teatro. 6ed. São Paulo: perspectiva, 2014.

BICALHO, Poliene Soares dos Santos. Se pinta e se veste: segunda pele indígena. 2018. Disponível em: https://dobras.emnuvens.com.br/dobras | e-ISSN 2358-0003. Acesso em: 20 de janeiro de 2019.

CARLI, Ana Mery S. de; VENZON, Bernadete L. S. Moda, sustentabilidade e emergências. Caxias do Sul, RS: Educs, 2012.

CIDREIRA, Renata Pitombo. O Sentido da Moda: vestuário, comunicação e cultura. São Paulo: Annablume, 2005.

CONRADO, Guido. Conceitos de Moda / Guido Conrado, Vânia Polly, Lu Caitora. Rio de Janeiro: SENAI/CETIQT, 2010.

DA MATTA, Roberto. Carnavais, malandros e heróis. $6^{\circ}$ ed. Rio de Janeiro: Rocco, 1997.

FLETCHER, Kate; GROSE, Linda. Moda e Sustentabilidade, design para mudança. Editora Senac. São Paulo, 2011

GODART, Frédéric. Sociologia da moda. Tradução Lea P. Zylberlicht. São Paulo: SENAC São Paulo, 2010.

GWILT, Alison. Moda sustentável: guia prático. 1. ed. São Paulo: GG.2014.

JATOBÁ, Waldick. Desafios do design sustentável brasileiro. São Paulo: Versal Editores, 2014.

LAVER, James. A roupa e a moda: Uma história concisa. São Paulo: Schwarcz, 1989. LINKE. Disponível em: http://www.cih.uem.br/anais/2013/trabalhos/ 188_ trabalho. pdf. Acesso em 15 de janeiro de 2019.

LIPOVETSKY, Gilles. O Império do efêmero: a moda e seus destinos nas sociedades modernas. 2. Ed. Companhia das Letras. 2003.

MANZINI, Ezio; VEZZOLI, Carlo. O desenvolvimento de produtos sustentáveis. São Paulo: Editora da Universidade de São Paulo, 2016.

MARTIN, Macarena San. Curso Prático: Designer de Moda. Escala Ltda; São Paulo, 2012.

MÜLLER, Florence. Arte \& Moda. São Paulo: Cosac \& Naify Edições, 2000.

MUNARI, Bruno. Das coisas nascem coisas. São Paulo: Martins Fontes, 1998.

PALOMINO, Erika. A moda. São Paulo: Publifolha, 2003.

SALCEDO, Helena. Moda ética para um futuro sustentável. São Paulo: GG, 2014. 
SANT'ANNA, Maria Rubia. Sociabilidades Coloniais: entre o ver e o ser visto. São Paulo: Estação das Letras e Cores, 2016.

SEIVEWRIGHT, Simon. Pesquisa e design - Fundamentos de design de moda. Porto Alegre: Bookman, 2015.

SEVERINO, Antônio Joaquim. Metodologia do trabalho científico. 23 ed. São Paulo: Cortez, 2007.

SIMILI, Ivana Guilherme; VASQUES, Ronaldo Salvador. Indumentária e moda: caminhos investigativos. Maringá: Ed. Universidade Estadual de Maringá, 2013.

SVENDSEN, Lars. Moda uma filosofia. Tradução Maria Luiza X. de A. Borges. Rio de Janeiro: Zahar, 2010.

TREPTOW, Doris. Inventando moda: planejamento de coleção. Brusque: D. Treptow, 2003.

VIANA, Fausto; MUNIZ, Rosane. Diário de pesquisadores: Traje de Cena. São Paulo: Estação das Letras e Cores, 2012.

VIANA, Fausto; BASSI, Carolina, Rosane. Traje de Cena, Traje de Folguedo. São Paulo: Estação das Letras e Cores, 2014.

Recebido em: 30/07/2019

Aceito em: 19/09/2019

DOI: http://dx.doi.org/10.5965/25944630332019113 